\title{
AEC and Challenges for Vietnam Insurance Market
}

\section{Thi Chinh Nguyen ${ }^{a}$}

\begin{abstract}
The ASEAN Economic Community (AEC) creates a common market for 10 member countries including Brunei, Cambodia, Indonesia, Laos, Malaysia, Myanmar, the Philippines, Singapore, Thailand, and Vietnam. Vietnam's participation in AEC will inevitably support insurers as well as Vietnam's insurance market in expanding and deepening its presence in the regional market, which contributes to the increasing need of insurance participation, attracting foreign-invested insurers to Vietnam insurance market, the renovation of management methods, the application of advance technology, etc. However, except from those opportunities, this also brings many challenges for the domestic market and insurance companies such as strong regional competition for insurance market, difficulties in accessing AEC insurance market, weak capacity in insurance technology and enterprises' capital sources, the shortage of international standards, and limitations in applying science and technology to management. The paper focuses on analyzing AEC insurance regulations; identifying which challenges Vietnam insurance market faces; and proposing recommendations to overcome these challenges.
\end{abstract}

\section{Keywords}

AEC, insurance, insurance market, challenges

On October 7, 2003, ASEAN (Association of Southeast Asian Nations) heads of states/government signed the Declaration of ASEAN Concord II in Bali, Indonesia. The agreement aims to establish and develop an ASEAN Economic Community (AEC).

The AEC has become one of the three pillars of the ASEAN Community (ASEAN Political-Security Community-APSC, the ASEAN Economic Community-AEC, and the ASEAN Socio-Cultural Community-ASCC). The AEC is composed of four pillars (see Figure 1).

\section{A SINGLE MARKET AND PRODUCTION BASE}

Implementing the AEC will make ASEAN to be a single market and production base, thereby it will contribute to enhancing ASEAN's competitiveness. The AEC will support the economic integration of priority areas and simultaneously allow the free flow of highly qualified human resources in region. An ASEAN single market and production base consists of five basic elements: free movement of goods; services; skilled labor; further liberalization of capital flows; and investment flows.

Tariff and non-tariff barriers will gradually be removed. ASEAN investors will be free to invest in any areas of the region, while experts and skilled

aNational Economics University, Vietnam

\section{Correspondent Author:}

Thi Chinh Nguyen, Faculty of Insurance, Room 102-103, Bld. 6B, National Economics University, 207 Giai Phong Rd., Hai Ba Trung Dist., Hanoi, Vietnam 


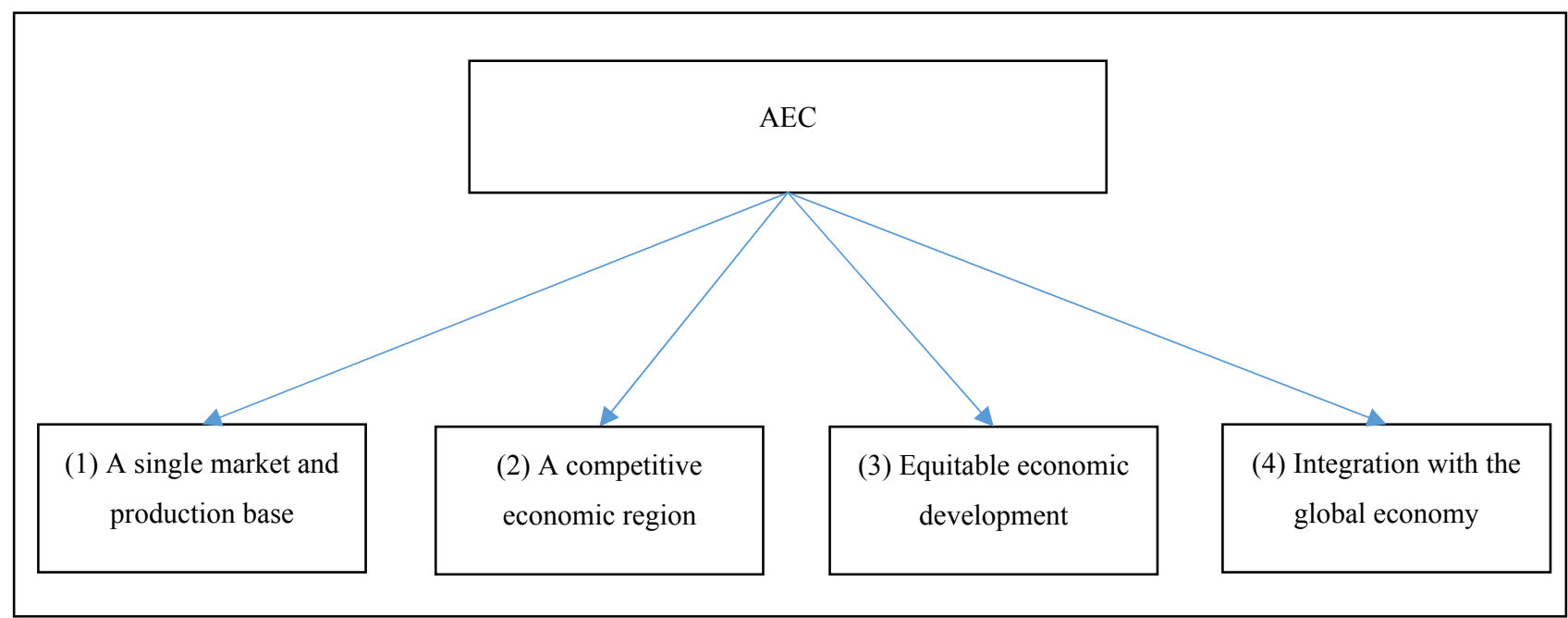

Figure 1. The Four Pillars of AEC.

Note: Source: Author.

workers are free to move as well. Customs and trade procedures, when being standardized in harmony and simplicity, will contribute to lower transaction costs.

A single market for goods and services will promote the development of regional production networks which will enhance ASEAN's capacity as a global manufacturing hub to meet the requirements of the global supply chain.

A single market and production base brings the benefit for priority industries such as agriculture, aviation (air freight), automobile, e-ASEAN, electronics, fisheries, health care, rubber, textiles and fashion, tourism, wood industry, and other logistics services.

\section{A COMPETITIVE ECONOMIC REGION}

The AEC aims to create a stable, prosperous, and highly competitive economic region that will prioritize six key factors: competition policy, consumer protection, intellectual property rights, infrastructure development, taxation systems, and e-commerce.

The AEC is committed to promoting a culture of fair competition through the issuance of competitive policies and laws, ensuring a level playing field in ASEAN and increasing regional economic efficiency.

\section{EQUITABLE ECONOMIC DEVELOPMENT}

The purpose of framework of ASEAN SME (Small and Medium Enterprises) development is to promote the region's competitiveness by facilitating access to information, finance, and skills, developing human resources and technology. These dynamics to fill the gaps between ASEAN member states, fostering economic integration in Cambodia, Laos, Myanmar, and Vietnam, allow member countries to move towards a common goal and to secure that these countries have equal interests in the process of economic integration.

\section{INTEGRATION WITH THE GLOBAL ECONOMY}

ASEAN countries can be considered to be operating in an increasingly globalized environment due to their interactive markets and integration industries. Therefore, besides AEC, ASEAN must also step further in considering all the regulations in the world to 
Table 1. Liberalization Commitments in the Insurance Industry of AEC Countries

\begin{tabular}{lll}
\hline No & Categories of insurance company & Member states commited to liberalization \\
\hline 1 & Life insurance & Indonesia, Philippines \\
2 & Non-life insurance & Brunei, Cambodia, Indonesia, Malaysia, Philippines, Singapore, and Vietnam \\
3 & Reinsurance & Brunei, Cambodia, Indonesia, Malaysia, Philippines, Singapore, and Vietnam \\
4 & Intermediate insurance & Brunei, Cambodia, Indonesia, Malaysia, Philippines, Singapore, and Vietnam \\
5 & Support industries of insurance & Brunei, Cambodia, Indonesia, Malaysia, Philippines, Singapore, and Vietnam \\
\hline
\end{tabular}

Note: Source: N. T. Dung. 2015. Integration-Challenges for Vietnam Insurance Market.

formulate their policies such as approving standards and production experiences, the most international distribution optima. This will be the main driving force for ASEAN to complete successfully with the global market, achieve its production goals, become an important supplier to the international market, and ensure the attractiveness of ASEAN market for foreign investors.

ASEAN member states also agreed to further join global supply chains by improving productivity and industrial efficiency. The AEC will become the focus of ASEAN with the active role of engaging with ASEAN FTA (Free Trade Area) partners and external economic partners in innovating regional structure.

In the insurance industry, the AEC is committed to the liberalization in several modes including: (1) Cross-border service provision-Insurance companies in ASEAN countries can directly provide their services to individuals and organizations in other ASEAN countries; (2) consumption outside the territory-Individuals and organizations in ASEAN countries are free to purchase insurance services in other ASEAN countries; (3) commercial presence-ASEAN insurance companies are allowed to establish companies or branches to operate in other ASEAN countries; and (4) presence of natural persons-Insurance professionals are free to seek employment and provide services in all ASEAN countries.
On the level of liberalization in the insurance industry, ASEAN countries have made basic commitments towards a full liberalization goal by 2020. However, for commitments to cross-border service provision, Brunei, Indonesia, Myanmar, and Singapore are still limited to or just opened for shipping services, international air, and transit goods. In commitments to trade presence, most countries have limited capital contributions which do not allow the establishment of international branches and using the right to consider applications for incorporation on a business benefit basis. In case of the presence of natural persons, all countries still do not approve.

Vietnam has now committed to liberalization under the AEC regulations, such as providing services to foreigners and foreign-invested projects and cross-border transport services on mode 1 , and there is no limitation on mode 2 (consumption outside the territory), allowing the establishment of branches of non-life insurance enterprises (mode 3). Table 1 shows the categories of insurance company and insurance support service which AEC member countries are committed to liberalization in the region.

On the other hand, the first ASEAN Insurance Summit in Singapore, held by the ASEAN Insurers Association (AIC) and the ASEAN Secretariat (ASEC) from September 3, 2014 to October 2, 2014, agreed on some basic commitments: Regional regulators support the process of liberalization and regional integration in the insurance industry. 


\section{VIETNAM'S INSURANCE MARKET ON INTEGRATION OF AEC}

Vietnam insurance market was formed after the promulgation of Government's Decree No. 100-CP of December 18, 1993. Before 1993, Vietnam insurance market had only one insurance company owned by the state-Bao Viet. Nowadays, the insurance market consists of more than 60 insurers, reinsurers, and insurance brokers which are licensed to establish, create a competitive market, provide more than 800 insurance products, and meet individuals' and economic organizations' diverse needs of insurance in society.

After more than 20 years of constructing and developing, Vietnam insurance market has gradually affirmed its role as a shield for organizations and individuals to participate in insurance contracts against risks and to help them quickly stabilize their life and business, as well as a long-term capital mobilization channel to invest in order to develop the economy, and create jobs for hundreds of thousands of workers.

The dynamics of economic growth mainly came from the non-life insurance market due to the development of trade and industry in Vietnam over the years. This fact is also shown by the increased share of non-life insurance premiums (in total premium revenues) over time, from $40.8 \%$ in 2005 (VND 5,535 billion in total premium revenues of VND 13,558 billion) up to $50.1 \%$ in 2014 (VND 27,391 billion in total premium revenues of VND 54,718 billion). The insurance market revenue has been increasing even during crisis period. In 2014, the insurance market's total premium revenue reached VND 54,718 billion, an increase of $14.89 \%$ compared to 2013 ; of which, non-life insurance revenue reached VND 27,391 billion, an increase of $12.45 \%$ compared to 2013 ; life insurance premium revenue reached VND 27,327 billion, up $17.44 \%$ compared to 2013 .

2015 is the final year to achieve the medium-term objective of Vietnam insurance market development strategy for the 2011-2015 period and the Decision No. 1826/QD-TTg dated December 6, 2012 by the Prime Minister approving the scheme on "restructuring of the securities market and insurance companies". In this context, the development of insurance market is quite positive. In 2015 , the market's total premium revenue is VND 68,688 billion, up $23.45 \%$ compared to 2014; premium revenue of non-life insurance reached VND 32,038 billion, growing $17.18 \%$ beyond 2014; life insurance premium revenue reached VND 36,650 billion, an increase of $29.5 \%$ compared to 2014 . Total indemnity from insurers in 2015 reached VND 21,562 billion; of which, life insurance companies paid VND 7,983 billion while non-life insurance businesses paid VND 13,579 billion. The total invested amount of insurance companies in 2015 reached 150,443 billion; rose $12.5 \%$ compared to 2014 ; of which, life insurance companies reached about VND 119,137 billion; went up $14.65 \%$ compared to 2014; Non-life insurance companies reached VND 31,306 billion, up 5\% compared to 2014. Additionally, the financial capacity of insurance companies has been strengthened. The market total assets in 2015 reached VND 193,158 billion (up 12.68\% compared to 2014); of which, non-life insurance companies had total assets of VND 61,499 billion (up 11\% compared to 2014); life insurance companies had total assets of VND 131,659 billion (up 13.48\% compared to 2014).

However, there are still considerable differences of market share allocation among the top five largest insurers in the non-life insurance market (see Figure 2) as well as the life insurance market (see Figure 3) with the remaining groups of insurance companies.

Although the domestic and global economy has experienced a prolonged period of crisis which affects almost all industries, insurance industry still finds its opportunities, even in 2010, 2011, and 2012, many life insurance companies in the market exceeded their business targets. That shows the potential growth of the insurance industry in Vietnam. 


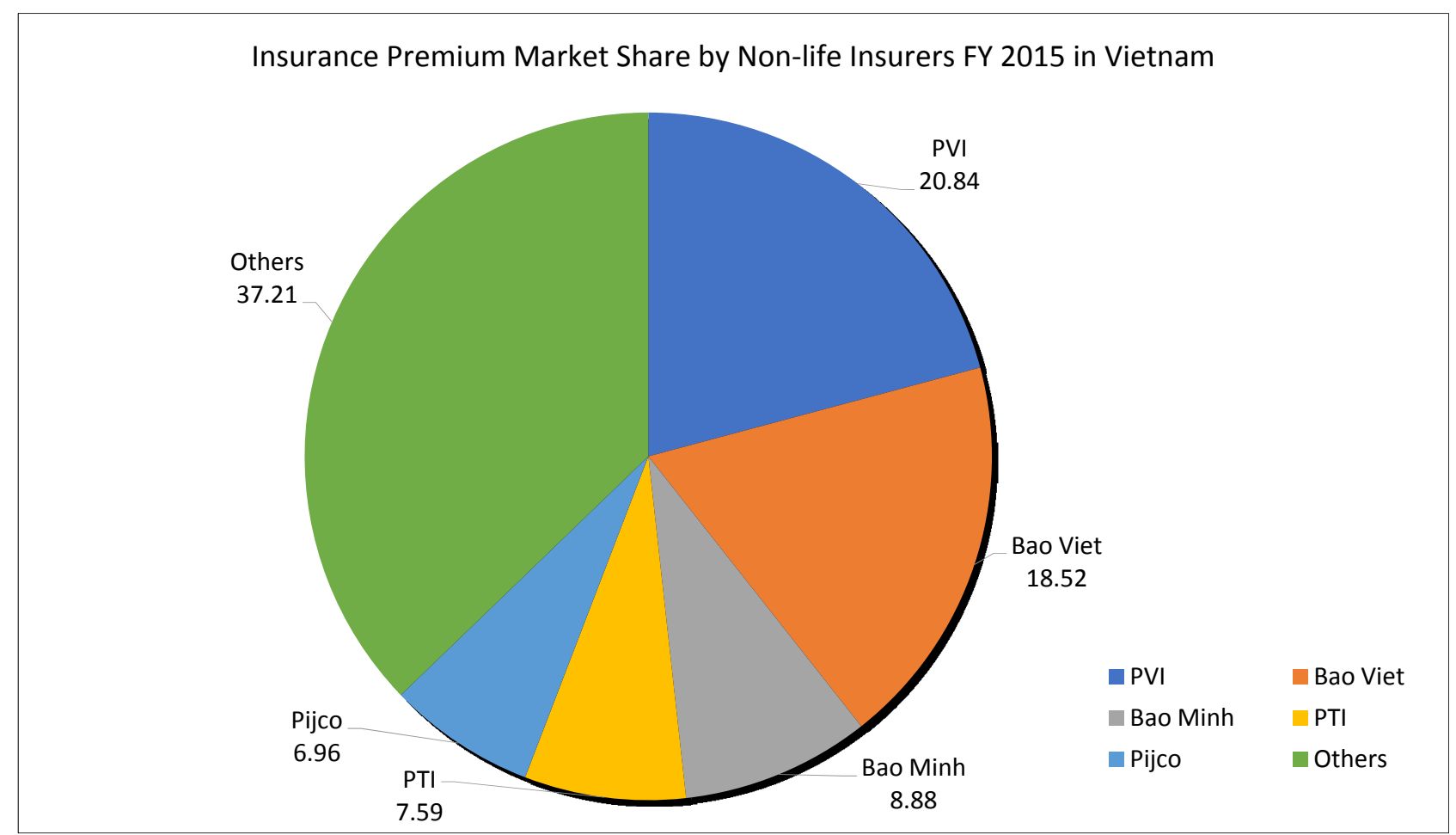

Figure 2. Insurance Premium Market Share by Non-life Insurers FY 2015 in Vietnam.

Note: Source: Overview of Vietnam insurance market in 2015, Insurance Supervisory and Authority, 2015.

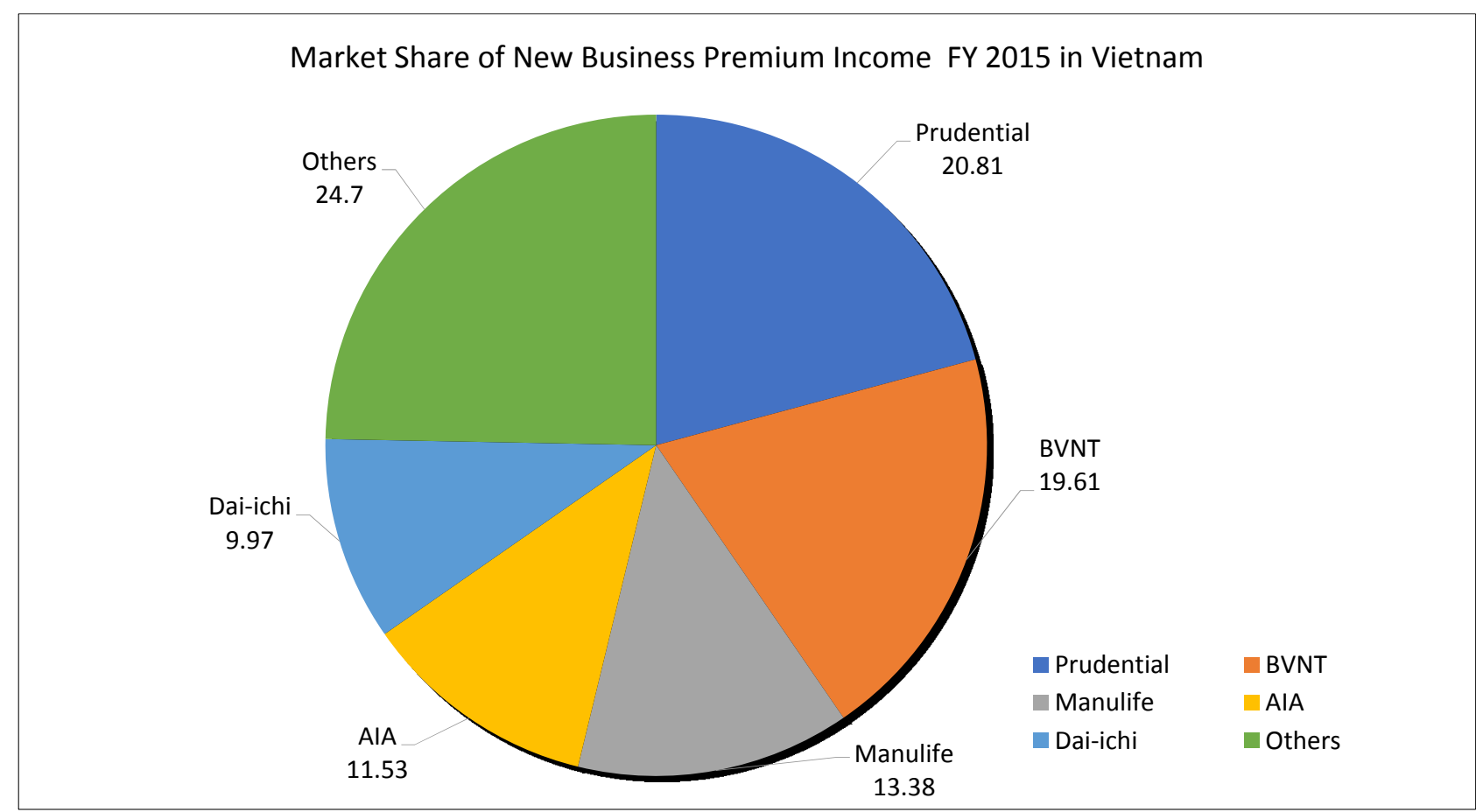

Figure 3. Market Share of New Business Premium Income FY 2015 in Vietnam.

Note: Source: Overview of Vietnam insurance market in 2015, Insurance Supervisory and Authority, 2015. 
In 2016, according to Vietnam Insurance Supervisory and Authority, total insurance premiums were estimated to be over VND 101,767 billion, of which, the non-life insurance revenue was estimated at VND 36,372 billion and life insurance revenue was estimated at VND 49,677 billion, and revenue from investment activities was estimated at VND 15,718 billion.

However, after more than 20 years of development, the contribution of Vietnam's insurance industry to GDP still remains relatively small. The current insurance premium income ratio is just below $2 \%$ of GDP, lower than that of the average ASEAN (3.35\%), Asia (5.37\%), and the world (6.3\%).

\section{JOINING THE AEC-CHALLENGES FOR VIETNAM'S INSURANCE MARKET}

Joining the AEC not only affects domestic trade or cross-border trade, but also affects service activities, especially financial services. In particular, the insurance industry with high international characteristics will be a major challenge for insurance enterprises in Vietnam insurance market.

\section{Firstly, Strong Competition From Insurance Markets in the AEC}

Firms in Vietnam insurance market will face strong competition from countries with more developed insurance industry. Undeniably, after the formation of AEC, Vietnamese insurers have been able to participate in the large-scale commercial-financial market, and receive many benefits, potential markets. However, Vietnam insurance companies will lose the opportunity to occupy the regional market, and it will also find it hard to maintain the domestic market if they do not exploit the market efficiently. In addition, insurers also face the labor competition. Highly qualified human resources from domestic insurers tend to move to bigger insurance corporations.

\section{Secondly, Difficulties in Accessing Insurance Market of AEC Countries}

The insurance premiums ratio to Vietnam's GDP is very low, accounting for $1.42 \%$, while the ASEAN average figure is $3.19 \%$ (see Table 2). In particular, for some developed countries such as Thailand, Malaysia, and Singapore, this figure is about $15 \%$ - This is a great challenge when Vietnamese insurance companies want to access their markets. Meanwhile, with the advantage of being more advanced, Thai, Malaysian, and Singaporean insurance companies possess more oppotunities than Vietnam itself.

Nevertheless, language proficiency and indigenous (native) culture are also a major barrier for Vietnamese insurance companies to access the AEC market.

\section{Thirdly, Challenges in Insurance Technology and Enterprises' Capital Sources}

Foreign insurance companies with greater advances in insurance technology, larger capital sources, can penetrate insurance lines which Vietnamese insurance companies has no capacity to develop yet; therefore, they will gain market share and regulate local insurance market. Meanwhile, the quality of available services is low, premiums and commissions are mainly competitive objects between insurance companies. Sales methods and channels still focus on traditional channels, and local companies do not fully utilize modern technology in marketing, consumer exploitation, and customer interaction.

\section{Fourthly, the Shortage of International Standards}

Upon joining the AEC, complying with international rules and standards are compulsory. However, the number of insurers who meet international standards, related techniques, finance, and human resources in Vietnam, is still limited. This also goes for specialized staffs, managers, and professional offfices. 
Table 2. Insurance Premium Volume to GDP (\%) of Vietnam Comparing to Other Countries and Regions

\begin{tabular}{llllllll}
\hline Vietnam & Philippines & Indonesia & $\begin{array}{l}\text { Asian } \\
\text { emerging } \\
\text { markets }\end{array}$ & $\begin{array}{l}\text { Emerging } \\
\text { markets }\end{array}$ & ASEAN & Asia & The world \\
\hline 1.42 & 1.4 & 1.77 & 2.96 & 2.65 & 3.19 & 5.73 & 6.5 \\
\hline
\end{tabular}

Note: Source: Swiss Re Institute. 2013. World Insurance in 2012.

\section{Fifthly, Limitations in Applying Science and Technology to Management}

The application of information technology to the management of Vietnam insurance companies has not integrated the management of customer records, and risk management before, during, and after issuing the policy through the computer system and the Internet. Hence, resulting in problems such as: due to the unavailability of a comprehensive and reliable customer data system and failure to control insurance fraud, companies have to recruit more staff to input data, manage invoices, prints... thereby increasing the expenditures.

\section{RECOMMENDATIONS FOR VIETNAM INSURANCE MARKET WHEN JOINING THE AEC}

In order to overcome those challenges, Vietnam insurance market needs to have solutions to maintain the domestic market and gradually occupy the regional market. Being more specific:

\section{For Insurers}

Vietnamese insurers should actively explore regional market and develop overseas investment. Penetrating new market should firstly seek permission to open a representative office, and research local market, legal system, before deciding whether or not to invest in/establish a company. After reviewing and evaluating new market, insurance companies should invest in shares/stocks of local businesses. This is a shortcut, which accelerates the expansion of operations in foreign markets. Companies that have good reputation and networks in their home country may be a ideal option for investment, as Vietnamese insurers do not have to start their own business systems or sales systems-This is a time-consuming, labor and capital intensive issue for insurers.

Additionally, Vietnamese insurance enterprises may establish $100 \%$ equity or joint venture with an host enterprise. If establishing a joint venture company, it is neccessary to increase your ownership percentage or turn it into a $100 \%$ owned company in long term to achieve the final goals.

In order to win a new market, one of the most important preparations is personnel. The main obstacle for Vietnam insurance companies is the host country's language and culture. Thus, if Vietnam insurance companies determine the strategy to expand their business into overseas markets in the region, they must prepare their personnel carefully because the process of language and culture training is time-comsuming issue.

Vietnam insurance firms need to improve their competitiveness and quality of service by applying information technology, which will tackle many problems and lead to improvements in products, service and management processes, cost savings, and preventing fraud. Information technology will improve the claim handling process, increase controlling through the software system, and reduce paperwork and complex procedures.

Standardizing staff in insurance industry towards international standards, especially for middle and 
senior level of enterprise managers. Collaborating with universities to provide basic and advanced training about insurance; executive management skills for insurance company officers; and access to internationally standardized programs such as ANZIIF (Australian and New Zealand Institute of Insurance and Finance), CII (Chartered Insurance Institute), LOMA (Life Office Management Association)-These are internationally recognized certificate programs in the region across the world.

\section{For the Organizations/Authorities Who Supervise Insurance Market}

The organizations/authorities who regulate/supervise Vietnam insurance market should actively participate in the Southeast Asia Insurance Management Forum and the International Association of Insurance Supervisors; also review and evaluate the compliance with the principles of management and supervision set by the International Association of Insurance Supervisors. On that basis, these organizations/authorities will be able to form and complete the mechanisms and procedures on insurance business more closely and be compatible with the regulations and agreements signed with the AEC, and international insurrance laws and practices.

The Ministry of Finance, the Insurance Association of Vietnam, and Vietnamese insurers must strengthen the monitoring and supervising activities of the implementation of the international integration process; regularly evaluate the impact of the integration process in order to adjust timely the mechanism and policies to maximize the positive impact and limit negative impact of the integration process.

It is necessary to promote the financial supervision and risk management in Vietnamese insurers. In Vietnam, financial supervision and risk management do not receive much of attention, and tools for monitoring are still not sufficient. The financial inspection and supervision agencies themselves have many shortcomings in human resources, technical facilities, and technologies for information collection and processing; quantitative, warning and risk analysis models for financial systems are rarely applied for remote monitoring. Hence, controlling and supervising the insurance market and financial system in the context of integration will be a mandatory solution in order to form a transparent insurance market.

\section{CONCLUSIONS}

After the first steps of formation, Vietnam insurance market has transformed into a new stage of international integration. The process of integration becomes stronger and more concrete. This is evident when Vietnam joins multilateral free trade agreements such as AEC. The integration of AEC has had significant impacts on Vietnam economy, financial market in general and insurance market in particular, thus it provides opportunities for nation development, but there are also many challenges for Vietnam insurance market. This paper outlines AEC regulations relating to insurance, clarifies the challenges for Vietnam insurance market, and suggests some recommendations to help domestic insurers overcome the challenges in Vietnam insurance market and develop and expand its business in regional insurance market. The recommendations suggested in the paper will contribute positively to the development of Vietnam insurance market.

\section{References}

Dung, N. T. 2015. Integration-Challenges for Vietnam Insurance Market. Stock investment. Retrieved (http://tinn hanhchungkhoan.vn/bao-hiem/hoi-nhap-nganh-bao-hiem-c hiu-thach-thuc-o-san-nha-120348.html).

Hoang, V. H. 2016. ASEAN Economic Community-Priority for ASEAN Economic Integration. Retrieved (http://www. mofahcm.gov.vn/mofa/nr091019080134/nr091019083649/ ns100805083136).

Hoi, H. V. 2013. "Participating in the ASEAN Economic Community and Its Impacts on Vietnam International 
Trade." Vietnam National University Journal of Science (Issue of Economics and Business). Ver. 29, vol. 4, pp. 44-53.

Insurance Supervisory and Authority. 2015. Overview of Vietnam Insurance Market in 2015. Retrieved (file://Users/ mss.chinh/Downloads/Nien\%20giam\%202015-p1.pdf).

Ministry of Finance. 2013. 20 Years Development of Vietnam Insuance Market: The Very First Milestone. Retrieved (http://www.mof.gov.vn/webcenter/portal/tttc/r/m/hdldb/hdl db_chitiet?dID $=79242 \& d D o c N a m e=B T C 313679 \&$ adf.ctrl -state $=15$ az5fxvhh_167\&_afrLoop $=2850644856111720 \#$ ! \%40\%40\%3FdID\%3D79242\%26_afrLoop\%3D285064485 6111720\%26dDocName\%3DBTC313679\%26_adf.ctrl-stat e\%3D8s202g4yw_4).

Phuong, H. 2016. Vietnam Insurance Market After Joining AEC-Opportunities and Challenges. Retrieved (http://fast 500.vn/Thi-truong-bao-hiem-Viet-Nam-hau-AEC-Co-hoi-v a-ap-luc-5162-1006.html).

Swiss Re Institute. 2013. World Insurance in 2012. Sigma
Research. Retrieved (http://media.swissre.com/documents/ sigma3_2013_en.pdf).

Thanh, N. D. 2014. Vietnam and AEC 2015. Saigon Times. Retrieved (http://www.thesaigontimes.vn/119601/Viet-Na m-va-AEC-2015.html).

Vietnam Insurance Market-Opportunities and Challenges in 2016. 2016. Retrieved (http://www.tca.com.vn/post/thi-tru ong-bao-hiem-viet-nam-nhung-co-hoi-va-thach-thuc-nam-2 016/IWZ9ZIUB.html).

WTO-VCCI Centre. 2015. Overview of ASEAN Economic Community. Retrieved (http://www.trungtamwto.vn/cachiep dinhkhac/tom-luoc-cong-dong-kinh-te-asean-aec).

\section{Bio}

Thi Chinh Nguyen, Ph.D., Insurance Faculty, National Economics University, Vietnam; research fields: insurance, finance, social security. 